\title{
Insurance Distribution Directive and Cross-Border Activities by Insurance Intermediaries in the EU
}

\author{
Isabelle Audigier
}

\section{Introduction}

The Insurance Distribution Directive (IDD ${ }^{1}$ ) came into force on 22 February 2016 and repealed the Insurance Mediation Directive $\left(\mathrm{IMD}^{2}\right)$. EU Member States were required to implement it into their national laws by 1 July 2018 and had to apply their national rules from 1 October 2018.

Despite the European passport granted to insurance intermediaries by the IMD in 2002, the single market for insurance distribution remained very limited and fragmented. One of the key objectives of the IDD was therefore to further facilitate cross-border activities of insurance intermediaries, thus promoting the emergence of a genuine Single Market in insurance services. ${ }^{3}$

This Chapter will present the new rules on the freedom to provide services (FOS) and freedom of establishment (FOE) introduced by Chapter III of the IDD and by $\mathrm{EIOPA}^{4}$ measures that apply to insurance intermediaries and ancillary intermediaries and will explain how they have partly simplified and clarified the procedure to

\footnotetext{
${ }^{1}$ Directive 2016/97 of the European Parliament and of the Council of 20 January 2016 on insurance distribution.

${ }^{2}$ Directive 2002/92/EC of the European Parliament and of the Council of 9 December 2002 on insurance mediation.

${ }^{3}$ The text is based on Article 53 (1) and Article 62 of the Treaty on the functioning of the European Union (TFEU), that is to say, mutual recognition of diplomas in case of freedom of establishment and restrictions to freedom to provide services.

${ }^{4}$ European Insurance and occupational pensions authority.
}

I. Audigier $(\triangle)$

BIPAR (The European Federation of Insurance and Investment Intermediaries), Brussels,

Belgium

e-mail: ia@bipar.eu

P. Marano, K. Noussia (eds.), Insurance Distribution Directive, AIDA Europe

Research Series on Insurance Law and Regulation 3,

https://doi.org/10.1007/978-3-030-52738-9_1 
operate cross-borders. The restrictions by the general good provisions of EU Member States will be explained, on the basis of recent reports provided by the Commission and EIOPA.

It will also detail the new division of competence between the home and host Member State competent authorities for ensuring intermediaries' compliance with the IDD requirements (in particular in the context of the new concept of primary place of business and in other exceptional situations) and will explain how this new balance could impact intermediaries' passporting rights. It will also focus on residual host Member States powers in some exceptional situations.

Finally, it will explore whether the IDD has led or will lead to more market integration. Part III will also briefly analyse the impact of 'Brexit', that is, the leaving of the EU by the United Kingdom, on cross-border activities of insurance intermediaries.

\section{Simpler and Clearer Rules for Cross Border Activities by Insurance Intermediaries?}

\subsection{Some Background}

In 2002, the European legislature explained that a first step to facilitate the exercise of freedom of establishment and freedom to provide services ${ }^{5}$ for insurance agents and brokers had been made by the 1976 Directive, ${ }^{6}$ followed by the 1991 Commission Recommendation ${ }^{7,8}$ that largely harmonised national provisions on professional requirements and registration of insurance intermediaries. However, barriers to the taking up and pursuit of the activities of insurance and reinsurance intermediaries in the internal market remained, and the inability for the latter to operate freely

\footnotetext{
${ }^{5}$ The freedom to provide services (FOS) and the freedom of establishment (FOE) are two of the fundamental freedoms existing between EU Member States, the others being the free movement of goods, persons and capital. Pursuant to Articles 56 to 62 of the Treaty on the Functioning of the European Union (TFEU), restrictions on the freedom to provide services within the Union are prohibited in respect of nationals of Member States who are established in a Member State other than that of the person for whom the services are intended. Likewise, pursuant to Articles 49 to 55 of TFEU, restrictions on the freedom of establishment of nationals of a Member State in the territory of another Member State are prohibited. The European Court of Justice has over the years extensively interpreted the two notions of FOS and FOE, establishing several principles interpreting the basic EU concepts.

${ }^{6}$ Council Directive 77/92/EEC of 13 December 1976 on measures to facilitate the effective exercise of freedom of establishment and freedom to provide services in respect of the activities of insurance agents and brokers.

${ }^{7}$ Commission Recommendation 92/48/EEC of 18 December 1991 on insurance intermediaries.

${ }^{8}$ Recitals 2 and 4, IMD.
} 
throughout the Community hindered the proper functioning of the single market in insurance. 9

In practice, an insurance intermediary who was not a member of an international network and who wanted to operate cross-border had to get several documents to make himself known in all concerned host EU member States and in some cases comply sometimes with their whole national legislation. It was a "dive in troubled waters". 10

The IMD took a second step and introduced a single passport for insurance intermediaries $^{11}$ : it provided a registration system for all insurance intermediaries based on a whole range of binding professional requirements aimed at enhancing consumer protection in insurance matters but also at facilitating intermediaries' cross-border activities. Registered insurance intermediaries were to be allowed to take up and pursue the activity of insurance mediation within the EU by means of both freedom of establishment and of services ${ }^{12}$ after going through a notification procedure. $^{13}$

With the IMD, insurance intermediaries were at last given the legal framework to play their role as the essential accompanying factor to the single licence scheme for insurance companies, which was introduced in July 1994.

It is interesting to recall that the IMD was the outcome of a very difficult compromise between the EU Member States due to the significant disparities that existed between the national legislations, some very developed (France and Spain for example) and some virtually non existent (for example, Germany).

The IMD provisions on cross-border notifications were further clarified in 2006 by the CEIOPS (now EIOPA) Luxembourg Protocol ${ }^{14}$ and then in 2008 by its revised version. The revised Protocol introduced an important "common understanding of freedom to provide services" by intermediaries. The protocol bound the existing CEIOPS members.

The Commission systematically plans evaluations of all adopted European legislation. In 2005 the Commission services initiated an implementation check of the

\footnotetext{
${ }^{9}$ Recitals 5 and 7, IMD.

${ }^{10} \mathrm{~B}$. Debuisson, La distribution transfrontalière des produits d'assurance. Plongée en eaux troubles, Université Catholique de Louvain, 1996 - Doc 96/26.

${ }^{11}$ As defined by Article 2.5, IMD.

${ }^{12}$ Article 3, IMD.

${ }^{13}$ Article 6, IMD.

${ }^{14}$ On 28 April 2006 the Committee of European Insurance and Occupational Pensions Supervisors (CEIOPS) published the Luxembourg Protocol relating to the cooperation of national supervisors in particular concerning the Insurance Mediation Directive (2002/92/EC). The Protocol developed the procedure for the exchange of information and co-operation in the supervision of insurance intermediaries' cross-border activities. It also promoted a consistent implementation of the registration and notification procedures by the presentation in its annex with special templates or standardised forms for those procedures. Its annexes also included a list of competent authorities for making and receiving notifications and a list of national bodies for out-of-court settlement of complaints.
} 
IMD and in May 2007, in its Green Paper on Retail Financial Services in the Single Market, the Commission explained that it was planning a complete review of the IMD in 2008/2009: "the IMD will be reviewed to ensure it is achieving its objectives of protecting consumers while promoting the Single insurance market". Also, Recital 139 of Solvency II Directive ${ }^{15}$ required the European Commission to put forward "as soon as possible and in any event by the end of 2010", a proposal for the revision of the IMD, "taking into account the consequences of the Directive for policyholders". As a first step the Commission asked CEIOPS to examine how the IMD had been implemented. This report was used as a basis for the revision of the IMD.

In July 2012, the Commission adopted a proposal for a Directive amending the IMD. One of the objectives of the proposal was to make it "easier for intermediaries to operate cross-border, thus promoting the emergence of a real internal market in insurance services". ${ }^{16}$ It proposed introducing a simpler notification process for intermediaries and ancillary intermediaries going cross-border as well as a centralized registration system and to clarify the application of the Treaty principles regarding the FOE and the FOS. We will see that the final text of the IDD that was adopted on 20 January 2016, after a four-year process by the two EU legislators, appears however to offer less clarity than intended.

The IDD has a wider scope than the IMD and applies to all insurance distributors, including insurance undertakings. However, the latter do not have to register ${ }^{17}$ under

\footnotetext{
${ }^{15}$ Directive 2009/138/EC of the European Parliament and of the Council of 25 November 2009 on the taking-up and pursuit of the business of Insurance and Reinsurance (Solvency II). Recital 139 provides: "Adoption of this Directive changes the risk profile of the insurance company vis-à-vis the policy holder. The Commission should as soon as possible and in any event by the end of 2010 put forward a proposal for the revision of Directive 2002/92/EC of the European Parliament and of the Council of 9 December 2002 on insurance mediation, taking into account the consequences of this Directive for policy holders".

${ }^{16}$ In the impact assessment accompanying the proposal, the Commission explained that "The market for cross-border insurance services in general, irrespective of the means of marketing, is still very limited in the retail insurance sector. Evidence suggests that only global and multinational business insurance intermediaries, serving major and multinational and domestic firms, and providing a wide range of services in addition to traditional brokerage, establish themselves in several Member States. When an intermediary wants to sell insurance products cross border under the freedom to provide services (FOS), it must notify its intention to the competent authority of its home member State (which must notify the host Member State) and go through a notification procedure. Several respondents to the public consultation from the insurance industry and insurance intermediaries, as well as EIOPA, acknowledged that there is room for improvement, modernization and increased transparency in this area. There are different approaches to the FOS problem in current EU legislation, all of which appear more favorable than that under IMD 1.

There is no single EU register for insurance intermediaries where a consumer can easily find information about registered sellers of different insurance products. As a consequence, sellers of insurance products lack easy access to information about how to go cross-border and this has a negative impact on competition in the EU insurance market".

${ }^{17}$ Article 3.1 (2) of the IDD.
} 
the IDD and their passporting rights remain governed by the relevant domestic provisions implementing the Solvency II Directive.

The IDD applies to ancillary intermediaries. ${ }^{18}$ Registered ancillary insurance intermediaries under the IDD will be allowed to operate under FOS and FOE. This is the first time this category of intermediaries has been granted a single licence. Under the IDD, ancillary insurance intermediaries are service providers and distributors of goods who distribute insurance products on an ancillary basis. The insurance products they distribute must be complementary to the good or the services they are selling. And they must not cover life assurance or liability risks, unless that cover complements the product or service which the intermediary provides as its principal professional activity. ${ }^{19}$ This chapter focuses mainly of the cross-border activities of insurance intermediaries. ${ }^{20}$

\subsection{A Simplified and Clearer Notification Procedure?}

Under the IMD, once the intermediary had informed its home Member State of its intention to operate cross-border in one or more Member States under FOS or FOE for the first time, the home Member State authority was required, within 1 month of receiving the information, to notify the competent authorities of the relevant host Member States. It had also to advise the applicant intermediary that it had done this. The intermediary could only commence its activities 1 month after the date of notification. The IMD allowed an exemption for the host Member State to be notified.

In practice, in cases where Member States chose to be notified-and they were a majority - this meant that an intermediary had to wait up to 2 months before being allowed to operate across borders. The approach of other Directives was more favourable: under MiFID, for example, an investment firm could go cross-border immediately upon notification by home to host Member States of the firm's intention

\footnotetext{
${ }^{18}$ Ancillary intermediaries are defined under Article 2(4) of the IDD.

${ }^{19}$ Article 1.3 of the IDD: Ancillary intermediaries are excluded from the IDD where: the insurance they sell covers the risk of breakdown, loss of or damage to the goods or non-use of the service, OR covers damage to or loss of baggage and other risks linked to travel booked with that provider; and where the amount of the premium for the insurance product does not exceed $€ 600$. In circumstances where the insurance is complementary to the good or service and the duration of that service is equal to or less than 3 months, the amount of the premium paid per person should not exceed $€ 200$.

${ }^{20}$ The notification procedure for ancillary intermediaries is similar to the one for insurance intermediaries. It is however important to note that the IDD requirements ancillary intermediaries need to comply with to be registered under the IDD (when not exempted by Article 1) differ slightly from the one of insurance intermediaries: Adapted appropriate knowledge and ability/CPD (can be proven by certificate), Good repute/clean record, PI cover (level established by MS according to nature of product and activity/Financial capacity, to act in the best interests of customers, no remuneration that conflicts with the duty to act in the best interests of customers, disclosure of nature and basis of remuneration, IPID to customer (non-life).
} 
to passport under FOS. This waiting period was sometimes problematic in a FOS context in particular, where intermediaries need to act sometimes quickly to cover their clients with establishment and exposure in other Member States.

In 2006 - and again in 2008 - this notification procedure was further clarified by the CEIOPS Luxembourg Protocol, and documents used to make the necessary notifications were harmonised. ${ }^{21}$ Building on the Protocol and the outcome of various consultations of the industry and Member States by the Commission, the IDD, in two separate articles (Articles 4 and 6), details different notification requirements for FOS and FOE activities.

Before starting business under FOS in another EU Member State for the first time, an intermediary must notify its home Member State competent authority of its intention to do so. It must communicate the following information ${ }^{22}$ to its home Member State: its name, address, registration number, the host Member State where it intends to operate, the category of intermediary (and name of insurer represented if appropriate) and the relevant classes of insurance. The home Member State communicates this within 1 month to the host member state competent authority concerned (which must acknowledge receipt without delay) and informs the intermediary about it. The home Member States must also inform the intermediary that, provided it complies with the general good provisions of the host Member States that are available on EIOPA and the host Member State websites, it can start its business. Any changes will have to be communicated by the intermediary to its home Member State that will communicate it to the host Member State.

In addition to the above requirements, EIOPA, in its 2018 Decision on the cooperation of the competent authorities with regard to the IDD (updated Luxembourg Protocol) ${ }^{23}$ states that the notification shall also specify the name of the

\footnotetext{
${ }^{21}$ Information such as for example the precise name of the intermediary, its address, the category it belongs to, the name of the insurer the intermediary is authorised to work for (if applicable), the classes of insurance for which the intermediary is authorised or the address of the online register in which details about the intermediary may be found, had to be included in the notification form transmitted by the home MS to the host MS. It was further clarified that all the documents had to be written in English or in another language agreed upon by the authorities concerned and that the authority of the host Member State must acknowledge receipt of the documents without undue delay by letter.

${ }^{22}$ Article 4(1), IDD.

${ }^{23} 28$ September 2018 EIOPA Decision of the Board of Supervisors on the cooperation of the competent authorities of the Member States of the European Economic Area with regard to Directive (EU) 2016/97 of the European Parliament and of the Council of 20 January 2016 on insurance distribution-EIOPA-BoS/18-340-The revision was needed to align CEIOPS (EIOPA)'s Luxembourg Protocol with the new IDD provisions (broader scope than the IMD, new chapter Freedom to Provide Services (FOS) and Freedom of Establishment (FOE), enhancement of exchange of information and cooperation between national competent authorities in registration and notification procedures etc.).

According to Article 2 of the Decision, it applies to all national authorities competent for the supervision of insurance and reinsurance distributors, which are Members of EIOPA and to the EEA EFTA Members of the Board of Supervisors of EIOPA to the extent to which the IDD is binding on them.
} 
current home competent authority, if different from the registration authority, the address of the online register in which details about the intermediary may be found and where available, the nature of the risks and commitments which will be covered by the insurance contracts which the intermediary intends to distribute in the host Member State.

Where the intermediary intends to operate, entirely or principally, in other Member State(s) on a FOS basis, the home competent authority shall consider communicating any other available information to allow the host competent authority to have a deeper knowledge of the FOS activity and facilitate awareness for ongoing supervision. An example of additional information that could be provided by the home competent authority to the host competent authority could be the provision of any available information resulting from discussions with intermediary about its business strategy and how its FOS activity fits into that strategy. While such information can be useful from a supervisory perspective, they may however, not always be available at the time they are being requested.

Any changes also have to be communicated by the intermediary to its home Member State that will communicate it to the host Member State. In its Decision, EIOPA explains that this could for example include the change of intention to provide insurance distribution activities by FOS in a specific host Member State in the future or the intermediary's removal from the register in its home Member State.

The removal of the "waiting period" of 1 month after the date of notification as well as the exemption for Member States not to be informed, are clearly improvements compared to the IMD approach. They facilitate procedure for activities under FOS and are in line with the objectives of the IDD. These two provisions had given rise to two problems: the timing for commencement of operations under FOS that was driven by the position of the host member State (not all Member States agreed to be notified) and the wait itself for an intermediary needing to insure its client's activities in a host Member State, for another month before able to do so.

It is important to note that the EIOPA Decision explains that the intermediary has to notify its intention to do business under FOS only in the Member State where the policyholder is established or has his residence, also in the case where the policyholder acts on behalf of different insureds and/or risks established or situated in one or more other Member States. ${ }^{24}$ This key explanatory narrative was included in the 2008 revised version of the CEIOPS Luxembourg Protocol and one can but regret that it was not transposed (at least into recitals) in the IMD. The clarity and legal certainty it brings are essential for cross-border activities.

As far as the IDD notification procedure to operate under FOE is concerned, the intermediary has to provide the same information as for the FOS notification, with in addition the address in the host member State from which documents may obtained and the name of any person responsible for the management of the branch or permanent presence. It still needs to wait up to 2 months before starting its activities in the concerned host Member States. During the second month, the host Member

\footnotetext{
${ }^{24}$ Section 2.2.1 of the EIOPA Decision, page 14 .
} 
State must communicate the general good provisions that are applicable in its territory to the home Member State of the intermediary and that latter authority must then inform the intermediary about it and that it can commence business in the host Member State territory, provided it complies with those legal provisions.

Any changes will have to be communicated by the intermediary to its home member state that will communicate it to the host member state. In its Decision, EIOPA explains that this could include the change of intention to provide insurance distribution activities on the territory of the host Member State through a branch or permanent presence or the intermediary's removal from the register in its home Member State.

The differentiation between the notification procedure for FOS and FOE activities, the harmonisation of information to be provided to the home Member State by intermediaries bring more clarity for all parties concerned. The information was already contained in the CEIOPS Luxembourg Protocol but that was less binding on the Member States. Also, the IDD addresses the changes made to notifications-this was only addressed in the CEIOPS Luxembourg Protocol— to ensure records are fully up to date. This is in line with better consumer protection which is one of the objectives of the IDD. One could regret that the passport notifications do not require the intermediary, who has applied for a passport to operate cross-border, to inform the concerned competent authorities whether it really does so. From a consumer protection and supervision point of view, it would be useful to know who is actually using the passport, and who is not. It is interesting to note that under the Solvency II Directive, insurance undertakings are required to report to their supervisory authority the amount of transactions carried out under the right of establishment and those carried out under the freedom to provide services, in host Member States. ${ }^{25}$

As mentioned earlier, the single passport under the IMD and now under the IDD is derived from the intermediary's registration in its home Member State. Like the IMD, the IDD requires the national registers to indicate the Member States in which "their" intermediaries conduct business under FOE or FOS. The $\operatorname{IDD}^{26}$ also requires EIOPA to establish, publish on its website and keep up to date a single electronic register containing records of insurance intermediaries which have notified to carry on cross-border business under FOE or FOS. The register must contain links to, and be accessible from, the website of each of the Member States' competent authorities.

Such a register, when available, will allow private but also commercial clients to quickly and easily find information about registered intermediaries operating crossborder in their respective countries. This is a positive improvement. For the time being EIOPA has established on its website a page with hyperlinks to national registers or single information points. ${ }^{27}$ EIOPA explains that its website serves as a provisional database of hyperlinks to national registers and that "it is assessing the

\footnotetext{
${ }^{25}$ Article 159, Solvency II Directive.

${ }^{26}$ Article 3(4), IDD.

${ }^{27}$ https://eiopa.europa.eu/Pages/Consumer-Protection/Single-electronic-register-for-cross-borderbusiness.aspx.
} 
most adequate long-term approach towards an online register by analogy to existing EIOPA registers to further enhance transparency and facilitate cross-border trade".

If it appears that the IDD has brought some much-needed and useful changes to the notification procedures, it has however missed an important opportunity that was "to clarify intermediaries' FOS/FOE activities", despite the fact that was one of the main objectives of the EU text.

\subsection{No Clarification Regarding the Triggering Element of Cross Border Activities}

The general objectives of the revision of the IMD were consumer protection, undistorted competition and market integration.

In the impact assessment accompanying the proposal for revision of the IMD, the Commission explained that one of the following preferred option would help addressing these objectives as "they involve slight costs and may trigger more cross-border trade": "option 2 would incorporate definitions already existing in the Luxembourg Protocol in the IMD (...). This option would clarify the application of Treaty principles regarding the FOE and the FOS and introduce some enforcement rules linked to those freedoms, based on the MIFID II." It further explained that "clarification of the definitions of FOE and FOS would render the cross-border process more effective".

However, there is no recital or article in the IMD II proposal, nor later in the adopted IDD, that defines these activities. This a matter of regret. For the sake of legal certainty it is necessary to have a clear description of the triggering element of the FOS activities of an intermediary (is it the location of the intermediary? of the client? of the risk? both?) because general good rules and stricter information requirements of the host Member State may have to be complied with by intermediaries when they are considered to be carrying out FOS activities in that Member State.

In addition, because of the new distribution of powers between host and home supervisors in the IDD, Member States can in certain cases impose national requirements upon intermediaries working on a FOS basis (for example, in the case of advice being mandatory for the sale of any insurance products in Member States like France $^{28}$ ). Therefore, it is necessary for the intermediary, but also for the supervisory authority and the consumer or client to know when intermediaries' activities are considered as FOS activities.

It is equally important for the same reasons to clearly describe the triggering element of the FOE activities of an intermediary.

Even if the draft text of the IDD included at one point during the trilogue phase, the useful EIOPA decision's (updated Luxembourg Protocol) definition of the

${ }^{28}$ Article 22.2, IDD. 
triggering element of an intermediary's FOS activity (see below), unfortunately no agreement could be reached to keep the definition in the final text of the Directive. The Commission Legal Services advised against it explaining that an EU Directive - that is secondary legislation-could not contain such a definition and that freedom of services can only be defined in the Treaty. This was a surprising position as clarity on territorial criteria was for example introduced by the Solvency II Directive regarding FOS business of insurers. ${ }^{29}$

\subsection{EIOPA Clarifications}

FOS and FOE need to be distinguished, for it makes a difference whether an insurance intermediary is acting under one or the other concept with respect to, for example, notification requirements (see above) or possible restrictions for the general good (see below).

In the absence of a judicial or regulatory definition of when an intermediary is likely to be pursuing cross-border activities under FOS, reference has been made since 2006 to the common understanding of "freedom to provide services" 30 of the CEIOPS Luxembourg Protocol that was replaced in September 2018 by the EIOPA Decision. The clarifications contained in the CEIOPS Luxembourg Protocol on the triggering element of insurance intermediaries' cross-border activities under FOS remained in the Decision of EIOPA, slightly adapted to include ancillary intermediaries.

EIOPA understands freedom to provide services in the case of intermediary to mean:

An Intermediary or Ancillary Intermediary is operating under freedom to provide services ("FOS") if it intends to provide a policyholder, who is established in a Member State different from the one where the Intermediary or Ancillary Intermediary is registered, with an insurance contract relating to a risk situated in a Member State different from the Member State where the Intermediary or Ancillary Intermediary is registered. ${ }^{31}$

\footnotetext{
${ }^{29}$ Under Article 13(9) the host Member State, i.e. the Member State of the provision of services, is the Member State of the commitment (life insurance) or the Member State in which the risk is situated (non-life insurance). In other words, an insurer is providing services under FOS if the risk/ commitment is situated in another Member State.

${ }^{30}$ This common understanding was presented in the revised CEIOPS Luxembourg Protocol as "the most workable definition in line with the objectives of the IMD regarding the intention of the intermediary, the creation of the Single Market and consumer protection" - See footnote 6 to point 2.2.3 of the Protocol.

${ }^{31}$ EIOPA decision provides a non-exhaustive list of examples regarding activity carried on under FoS:

- An Intermediary or Ancillary Intermediary is actively marketing, providing insurance distribution services or seeking business from a customer resident or established in another Member State.
} 
In practice, this means for example that an intermediary having its office in Antwerp and intending to procure property insurance to a Belgian client with regard to the client's holiday house in the Netherlands, would not provide cross-border mediation services in the Netherlands as only the risk to be covered is situated in another Member State, whereas the client has his habitual residence in Belgium.

However, an intermediary with its office in Karlsruhe (Germany) and intending to procure fire insurance to a French client in Strasbourg (France), would be providing cross-border mediation services in France. It would have to notify his intention to carry out cross-border business into France under FOS.

Even though such definition is not binding upon the courts, it can be expected to be adhered to by the Competent Authorities provided no overruling definition has been adopted by legislation or a Community Court. Depending on national legislation implementing the IDD, local courts could also rule that the location of the client is the only criteria as to when national general good rules apply to a foreign insurance intermediary providing insurance distribution services to a local client. ${ }^{32}$ Article 22 of the IDD on information exemptions and flexibility clause also seems to refer to that unique criteria.

In their July 2019 report on cross-border supervision of retail financial services, ${ }^{33}$ the European Supervisory Authorities (ESAs) admit that they "have noticed that the legislation reviewed lacks clear criteria for determining the location where the

- An Intermediary or Ancillary Intermediary asks for and organises on its own initiative meetings with customers established in another Member State.

- Regarding advertisement: an Intermediary or Ancillary Intermediary gives/sends information on specific products, conditions etc. to selected groups of customers established in a given country/ in specific languages of some Member States etc. Here the advertisement has an active character, the intention of the Intermediary or Ancillary Intermediary to contact customers in another Member State is clear.

- Regarding electronic distance or distance marketing activities: If the content of the website of an Intermediary or Ancillary Intermediary is general and only in the language of the Member State of the Intermediary or Ancillary Intermediary, if it is not addressed to a specific group of customers or customers in specific Member States and when the customer is not able to directly or indirectly conclude an insurance contract using a website or other media, then the Intermediary or Ancillary Intermediary cannot be considered as actively seeking these customers and therefore cannot be considered as having the intention to do FoS in the Member State, where those customers are established. If an Intermediary or Ancillary Intermediary is contacted by those customers, it will not be considered as an intention to write business under FoS in the Member State of residence or of establishment of these customers.

- Where an Intermediary or Ancillary Intermediary opens a branch in another host Member State under freedom of establishment and where this branch sells insurance contracts to residents of the Intermediary's or Ancillary Intermediary's home Member State, it shall not be deemed as being an activity provided under FoS.

${ }^{32}$ BIPAR/Steptoe: The insurance Distribution Directive: A handbook on cross-border insurance distribution by insurance intermediaries-January 2019.

${ }^{33}$ ESAs report on cross-border supervision of retail financial services, 9 July 2019, JC/2019-22_-In this report the ESAs carried out a general mapping of the main Level 1 provisions for the different financial institutions operating across borders. The EU directives and regulations that the ESAs have reviewed include amongst others, the IDD, the SII and the MiFID 2. 
services is provided, which is key to determining whether there is cross-border provision of services and whether it falls under the FOS and the FOE, and as a consequence, which Competent Authority is responsible for its supervision. This lack of clear criteria is even more problematic when services and products are provided through digital means".

In their conclusions and suggestions for EU co-legislators, the ESAs further explained that they "are of the view that more clarity on this issue cannot be provided through Level 3 work and that such clarity should be provided by the $E U$-co-legislators, especially in the light of the growing phenomenon of the digitalization of financial services".

Although late, the recognition by the ESAs of this key issue is welcome. It is however, quite frustrating to read such a statement when market's associations have been drawing the attention to this lack of clarity for years before the adoption of the IDD and when it seems that action is now required only because it is problematic to services being provided via digital means It is also surprising to see that the ESAs do not believe that clarity on the issue could be brought by level 3 work when EIOPA itself introduced such clarity in its 2018 Decision.

It has always been less challenging to determine whether an intermediary is operating in another EU Member State on a FOE basis, since a FOE activity has a clearer cross-border element. The IDD has also slightly clarified the concept of FOE for IDD purposes: an intermediary is operating under FOE in another Member States if the intermediary establishes a branch-defined in the IDD as "an agency or a branch of an intermediary located in the territory of a Member State other than the home Member State ${ }^{, 34}$ - or a permanent presence that is equivalent to a branch unless the intermediary lawfully sets up such a permanent presence in another legal form. ${ }^{35}$

In its Decision, EIOPA simply states that it understands freedom of establishment, in the case of intermediaries and ancillary intermediaries, as meaning if they intend to carry out of insurance distribution activities through a branch or permanent presence established in a different Member State according to Article 6(1) of the IDD.

Even if under EU law the notion of "establishment" includes branches, it is surprising and somehow confusing that the IDD definition of the "host Member State" does not expressly mention a branch-as the Solvency II Directive does, for example—but only refers to a permanent presence or establishment.

\footnotetext{
${ }^{34}$ Article 2.1 (12), IDD.

${ }^{35}$ Recital 25, Article 6.1, IDD.
} 


\subsection{General Good Rules: Will More Transparency Be Enough to Avoid Their Possible Detrimental Impact on the Single Market?}

As explained above, the principle under the IDD-like under the IMD-is that the single registration in the home Member State triggers the provision of the EU passport to the insurance intermediaries subject to the appropriate notification procedure. However, as recalled in the EIOPA 2019 report analysing national general good rules, ${ }^{36}$ "the basic principle underlying the general good in the insurance sector is that (...) insurance intermediary operating under the (..) arrangements laid down by the IDD, is obliged to adapt its activities to the host Member States' rules if the measures enforced against it serve the general good, irrespective of whether it carries on those activities" through FOS or FOS.

Despite increased clarity and transparency introduced by the IDD and a greater role given to EIOPA, the effect of some of these general good rules can be challenging for intermediaries operating cross-border and be detrimental to the proper functioning of the IDD and the Single Market for insurance distribution.

Under the IMD, the competent authorities of the host Member State could decide "to take the necessary steps to ensure appropriate publication of the conditions under which, in the interest of the general good, intermediaries' business under FOS or FOE must be carried on in their territories". 37 The IDD makes the publication mandatory and introduced more requirements as well as an additional criterion as explained below.

Member States competent authorities must publish on their websites the general good rules that apply in their respective territory and update them regularly. ${ }^{38}$ Links to the websites of each Member State competent authorities must be available on the EIOPA's website "with all national general good rules categorised into different areas of law". Each Member State must also designate a single point of contact for providing information on its general good rules.

There is no real definition of what constitutes a general good rule in the IDD or in another EU text or in the CJEU case law. However in its Interpretative Communication, ${ }^{39}$ the Commission lists a number of cumulative (but not definitive) conditions for a general good rule to be valid under the EU law and that have been developed by the CJEU over the years: it must govern a matter which has not been harmonised at the EU level; the rule must pursue an objective of the general good; it must be non-discriminatory; objectively necessary and proportionate to the objective pursued

\footnotetext{
${ }^{36}$ EIOPA: Insurance Distribution Directive-Report analysing national general good rules - 22/07/ 2019.

${ }^{37}$ Article 6.3, IMD.

${ }^{38}$ Article 11, IDD.

${ }^{39} \mathrm{OJ}$ of the EC, C43/5 - 16-2 -2000-Commission interpretative communication on the freedom to provide services and the general good in the insurance sector.
} 
and the general good objective is not safeguarded by the rules of the provider's home Member States.

As rightly noted by EIOPA in its report, ${ }^{40}$ the IDD provides an additional criterion ${ }^{41}$ regarding how "general good' rules should be applied by Member States for insurance distribution, namely "the administration burden stemming from general good provisions should be proportionate with regard to consumer protection". One could wonder whether this criterion could be interpreted as a limitation of the IDD general good rules, meaning that these rules can only aim at protecting consumer and therefore can't applied to professional clients/SMES or in relation to large risks.

Under the IDD, a minimum harmonisation text, the national general good rules may relate to stricter rules in areas expressly mentioned in the Directive and stricter rules relating to other matters covered by the Directive. The IDD includes 11 options which allow Member States exercising them to introduce general good rules in their context. ${ }^{42}$ The EIOPA report provides a quite comprehensive though not exhaustive overview of those rules that Member States have introduced so far in the context of their national implementation of the IDD. It seems for example that a majority of Member States have used the options provided in Article 22 of the IDD to introduce stricter information requirements, mandatory advice for the sale of any insurance products and limitation or prohibition of remuneration paid to insurance intermediaries in relation to the distribution of insurance products.

More time and hindsight are needed to have a correct understanding on how these national general good rules can have an adverse effect on intermediaries' crossborder activities. However, it appears already that some national legislations that implement the IMD could be an obstacle to the proper functioning of the IDD Single Passport.

One example is the Romanian secondary legislation implementing the IDD. It states that the cooperation of foreign insurance distributors, including insurers carrying out activity in Romania on the basis of FOS with local intermediaries, must be based on reverse solicitation and the duration of that cooperation cannot be more than 3 years. ${ }^{43}$ It seems that this legislation is aimed at protecting consumers from "dubious" EU insurers operating under FOS in Romania and at preventing intermediaries from working with them and to ensure that consumers are not left without cover. However, if after 3 years the insurer operating under FOS in Romania is no longer able to collaborate with the same intermediary, it can still operate in Romania under FOS with different intermediaries.

These rules do not appear to meet the objective of consumer protection and have significant consequences for local Romanian insurance brokers as they are no longer

\footnotetext{
${ }^{40}$ See footnote 19 .

${ }^{41}$ Article 11 (2).

${ }^{42}$ Annex 1 of EIOPA report analysing national general good rules.

${ }^{43}$ EIOPA - Country-by-country analysis of national general good rules-Annex III to the Insurance

Distribution Directive: Report analysing national general good rules, - Romania, page 82.
} 
able to put in place long-term partnerships with EU insurers authorised to work on a FOS basis in Romania, thus hindering their ability to fully serve their clients' interests. In such a context, the introduction of Insurance Guarantee Schemes at EU level-to protect private policyholders by compensating for their claims in the event an insurance company becomes insolvent (in particular in the framework of cross-border activities and failures) - and more supervisory control on cross-border insurers would perhaps be more appropriate. This would also support a drive towards a single market.

It is interesting to note that in October 2019, the European Commission sent a letter of formal notice to Romania regarding the conditions for the sale of insurance products by insurance distributors from other Member States: "The Commission urges Romania to adjust national rules setting restrictive conditions insurance distributors from abroad who want to sell products to Romanians. (...) These conditions prevent insurance distributors from making effective use of their basic freedom to provide services within the internal market". ${ }^{4}$

The reaction of the Romanian supervisor to "protect" its market from insurers operating under FOS or FOE in their market is not an isolated case. Over recent years there have been failures of insurers operating in some Member States under FOS or FOE, and Member States are starting to think of solutions to protect their respective markets and consumers. In France, for example, the FFA (the French Federation of Insurers) published in May 2019 a position paper on "Strengthening the Internal Market by tackling failures of insurance companies operating under FOS". It explains that since November 2016, the French insurance market has been experiencing numerous run-offs, or failures of insurers authorised in the EU and operating in France under FOS. The FFA has advanced concrete proposals aimed at preventing default by operators operating in the EU under FOS. ${ }^{45}$

These failures have an important disruptive impact on local markets and might lead the public to wonder about the efficiency and effectiveness of supervision within the Single Market. However, this should not bring into question passporting rights for insurers and intermediaries. There is obviously a need for a review of the supervision system of insurers operating cross-border and for a better cooperation amongst supervisors in the EU. It is expected that the current review by the European Commission of the Solvency II Framework, and in particular its part on the supervision of cross-border activities of insurers and the possible need of minimum harmonised rules on Insurance Guarantee Schemes (IGS), will suggest solutions to this serious issue.

The Directive amending Solvency II in the context of the ESAs review ${ }^{46}$ has already introduced some positive changes in this respect: the cooperation between

\footnotetext{
${ }^{44}$ European Commission's website, press corner, 10-10-2019.

${ }^{45}$ https://www.ffa-assurance.fr/ - Document de position: Renforcer le marché intérieur en luttant contre les défaillances d'entreprises d'assurance qui opèrent par voie de LPS.

${ }^{46}$ Art. 2 of Directive (EU) 2019/2177 of the European Parliament and of the Council of 18 December 2019 amending Directive 2009/138/EC on the taking-up and pursuit of the business
} 
the NCAs and also between EIOPA and the NCAs is strengthened in relation to cross-border activities carried out by insurance undertakings. For example, the supervisory authority of the home Member State will have to notify EIOPA and the supervisory authority of the relevant host Member State where it identifies deteriorating financial conditions or other emerging risks posed by an insurance or reinsurance undertaking carrying out activities based on the freedom to provide services or the freedom of establishment that may have a cross-border effect. In its opinion on the 2020 review of Solvency II, EIOPA ${ }^{47}$ also advises to amend Article 36 of the Solvency II Directive by adding a new paragraph 7 as follows:

7. In case of material cross-border insurance business under the right of establishment or the freedom to provide services, the supervisory authority of the home Member State shall actively cooperate with the supervisory authority of the host Member State to assess whether the insurance undertaking has a clear understanding of the risks that it faces, or may face, in the host Member State.

This cooperation shall cover at least the following areas:

(a) system of governance including the ability of the head office management to understand the cross-border market specificities, risk management tools, internal controls in place and compliance procedures for the cross-border business;

(b) outsourcing arrangements and distributions partners;

(c) business strategy and claims handling;

(d) consumer protection.

8. Where appropriate, the supervisory authority of the home Member State shall inform in a timely manner the supervisory authority of the host Member State about the outcome of its supervisory review process which concerns the cross-border activity, in particular where the supervisory authority of the host Member State has already raised concerns.

Lastly, it is also interesting to note, that amongst EIOPA's follow-up actions to address the issues identified in its report on the general good, is the analysis from a legal and supervisory perspective of general good rules imposed on incoming insurance intermediaries in areas of the home Member State competence such as registration requirements. As this is clearly a matter for home Member State competence and the IDD single licence for intermediaries is based on the single registration in the home Member State, it is hoped that follow-up actions will indeed be taken in this area.

of Insurance and Reinsurance (Solvency II), Directive 2014/65/EU on markets in financial instruments and Directive (EU) 2015/849/ on the prevention of the use of the financial system for the purposes of money-laundering or terrorist financing, OJ L 334, 27.12.2019, p. 155.

${ }^{47} \mathrm{https}$ ///eiopa.europa.eu/Pages/Consultation-Paper-on-the-Opinion-on-the-2020-review-of-Sol vency-II.aspx. 


\section{New Division of Competence Between Home and Host Member State Authorities and the Possible Impact on Intermediaries' Passporting Rights}

Under the IMD, the only power clearly given to host Member States over insurance intermediaries operating under FOS or FOE in their markets, was the one to adopt specific legal provisions to protect the general good. They could ensure the appropriate publication of the conditions under which, in the interest of the general good, the business concerned must be carried on in their territories and take appropriate measures to prevent or to penalise those irregularities committed in their territories which are contrary to their general good measures. ${ }^{48}$

The IMD did not, however, clearly divide competences between home and host member State competent authorities. This led some EU regulators, such as the UK's Financial Conduct Authority (FCA), to claim authority to take enforcement action against all EU intermediaries passporting into the UK and claim jurisdiction over all activities of UK firms passporting into other EU states.

The IDD brought an important change to the framework established by the IMD: it clearly divides the oversight powers between the home and host Member States competent authorities over insurance intermediaries who are passporting in the EU. Although this division of competence aims to ensure the compliance of intermediaries with the IDD requirements, one could wonder whether the powers given by the IDD to the host Member States, in addition to an (excessive) use of the general good rules could not weaken or go against the concept of the IDD Single Licence.

\subsection{Powers Given to Host Member States Over Intermediaries Operating Under FOS in Their Territories}

The IDD does introduce new powers as far as FOS activities of insurance intermediaries are concerned. Like under the IMD, when operating under FOS, an insurance intermediary must comply with the minimum requirements of the IDD as implemented in its home member State and the general good rules of the host Member State.

At the time of the trilogue, the Council of the EU had explained that the intention was here to strike a proper balance, taking inspiration from relevant legislative texts such as the Solvency II Directive and the Mortgage Credit Directive: "We considered that a proper solution aimed at enhancing consumer protection, while preserving a smooth functioning of the passport, might come from graduating competences and powers differently in the cases of freedom to provide services and freedom of

$\overline{{ }^{48} \text { Article } 6.3 \text { and article } 8.4 \text {, IMD. }}$ 
establishment and introducing appropriate safeguards in order to clarify supervisors' powers and to avoid regulatory arbitrage".

The IDD makes clear that in case of intermediaries' FOS activities, the home Member State competent authority will be responsible for ensuring compliance with all IDD requirements (such as good repute, professional knowledge and competence, and conduct of business obligations) with regard to all business activities of the intermediary within the internal market. ${ }^{49}$ And - as under the IMD—-the host Member State competent authority can take appropriate and non-discriminatory measures to penalise any failure of the intermediary to comply with its general good rules and prevent it from carrying out new business.

If the host Member State competent authority considers that the intermediary operating under FOS is in breach of any IDD requirements ${ }^{50}$ (for example, breach of the rules on good repute), it will inform the home Member State competent authority which should then take appropriate measures against the intermediary to remedy the breach. Further clarity is also introduced by the EIOPA Decision. ${ }^{51}$

In exceptional situations, ${ }^{52}$ the competent authority of the host Member State is entitled to intervene and take measures against the incoming intermediary if it continues acting in a way that is clearly detrimental to the interests of consumers of the host Member State on a large scale, or to the orderly functioning of the host Member State (re)insurance market, despite the measures taken by the home Member State or where it fails to take any. The host Member State can also intervene in urgent cases ${ }^{53}$ to prevent or penalise breaches by the intermediary in the host Member State, where it is necessary to protect the rights of the consumers in the host Member State. In such cases the competent authorities of the host Member State have the right to prevent the intermediary from carrying out new business within the territory of the host Member State. EIOPA is also granted with some powers in this context. The home or host Member States may request its assistance to settle disagreements between them in such cross-border situations. ${ }^{54}$

These enhanced powers of the host Member States in a FOS context clearly reinforce some safeguards for the consumers. Time will tell however whether these new powers given to the host Member States and EIOPA will hinder or not intermediaries' cross-border activities.

The IDD goes even further and introduces new powers for host Member States to help them preventing the circumvention of their rules by insurance intermediaries. ${ }^{55}$ The competent authorities of the host member States have the right to prevent a foreign intermediary from carrying out business in its Member State if the

\footnotetext{
${ }^{49}$ Recital 21, IDD.

${ }^{50}$ Article 5.1, IDD.

${ }^{51}$ Section 3.2 of EIOPA Decision.

${ }^{52}$ Article 5.1 (3).

${ }^{53}$ Article 5.2, IDD.

${ }^{54}$ Article 5.1, IDD that refers to Article 19 of Regulation No 1094/2010.

${ }^{55}$ Article 9, IDD.
} 
intermediary's activities are entirely or principally directed towards its territory with the sole purpose of avoiding the legal rules which apply to local intermediaries of the host Member State. They have equivalent powers in cases where the intermediary's activity seriously endangers the proper functioning of the (re)insurance market in the host Member State in terms of consumer protection.

This crystalized in the IDD the ECJ case-law concerning freedom to provide services, clarifying that the host authority is entitled to take appropriate measures to prevent forum shopping aimed at avoiding falling within the competence of a specific legal framework.

\subsection{Powers Given to Host Member States Over Intermediaries Operating Under $\mathrm{FOE}$ in their Territories}

In the case of the establishment of a branch or a permanent presence in another Member State, the IDD distributes new responsibility for enforcement between home and host Member States and introduces the new concept of a "primary place of business ${ }^{56, "}$.

The home Member State remains responsible for ensuring that the intermediary, including its establishments in host Member States, complies with its IDD obligations affecting the business of the intermediaries as a whole: rules on good repute, professional knowledge and competence. ${ }^{57}$ As with the provision of services regime, if the competent authority of the host Member State suspects any breaches of these requirements, it must inform the competent authorities of the home member State. The competent authority of the host Member State is entitled to intervene if the home Member State fails to take appropriate measures or if such measures are insufficient. ${ }^{58}$ EIOPA is also granted with some powers in this context. The home or host Member States may request its assistance to settle disagreements between them in such cross-border situations.

The competent authorities of host Member States are responsible for ensuring that the intermediaries' branches that provide services in their territories comply with the IDD conduct of business and information requirements as implemented by them. The host Member State can take measures if the branch breaches these requirements. More powers are given to the host Member States in this context, as they are entitled to examine the establishment arrangements of an intermediary in their territories and request changes to enable them to correctly enforce the obligations of the intermediary. ${ }^{59}$

\footnotetext{
${ }^{56}$ Article 7, IDD.

${ }^{57}$ Article 8, IDD Section 3.2.2 of EIOPA Decision.

${ }^{58}$ Recital 22, IDD.

${ }^{59}$ Article 7(2) and 8(1), IDD.
} 
It is clear here that the EU legislators perceived the need to enhance consumer/ client protection as a priority, even if at the cost of some possible limitations to the functioning of the IDD passport.

The IDD introduces a new concept of the "primary place of business" into the insurance distribution sector. This is "the location from where the main business of an intermediary is managed" ${ }^{60}$ If the intermediary's primary place of business is in a Member State other than its home Member State, the relevant competent authority may then agree that the competent authority of the Member State of the primary place of business will act as if it were that of the home Member State. In such a situation, the competent authority of the primary place of business will oversee the intermediary's compliance with professional and organisational requirements, and information and conduct of business rules. This competent authority will also have the right to impose sanctions against the intermediary in the case of non-compliance.

It is very likely that the new concept of the "primary place of business" will have to be further clarified by EIOPA in order to ensure that Member States have the same understanding of it and that the division of competence is clearly organised between the competent authorities when needed. It is surprising that EIOPA decision ${ }^{61}$ is silent on the new concept (for example, what does the word "managed" mean in this context).

Together with the power given to Member State competent authorities to prevent the circumvention of the host Member States rules, this new concept empowers host Member States to better protect their consumers and markets. It encourages them to better cooperate to ensure better supervision of the distributors operating in their market. Without such a provision, the Member State where the intermediary is established but not that where its primary place of business is located, would have little incentive to supervise the conduct of the intermediary's activities. Equally the Member State where the primary place of business of the intermediary is located would have little power to properly supervise the activities of the intermediary.

The risk of prioritising the supervision of domestic markets was one of the issues mentioned in the ESAs report on cross-border supervision of retail financial services, and one that the competent authorities must face. However, in the report, the ESAs note that some of the most recent legislation reviewed, such as the IDD, will be helpful for tackling such an issue.

\footnotetext{
${ }^{60}$ Article 2.1 (14), IDD.

${ }^{61}$ The notification procedure for ancillary intermediaries is similar to the one for insurance intermediaries. It is however important to note that the IDD requirements ancillary intermediaries need to comply with to be registered under the IDD (when not exempted by Article 1) differ slightly from the one of insurance intermediaries: Adapted appropriate knowledge and ability /CPD (can be proven by certificate), Good repute/clean record, PI cover (level established by MS according to nature of product and activity/Financial capacity, to act in the best interests of customers, no remuneration that conflicts with the duty to act in the best interests of customers, disclosure of nature and basis of remuneration, IPID to customer (non-life).
} 


\section{Towards More Cross-Border Activities of Insurance Intermediaries?}

As mentioned earlier, one of the objectives of the IDD was to make it easier for insurance intermediaries to carry out cross-border activities using IDD passports, ensuring more market integration and more consumer protection. As explained in the ESAs report on cross -border supervision of retail financial services: "The increase in the cross-border provision of financial services has benefits for consumers, as it fosters competition and expands the offer available to consumers, who then have a broader number of financial institutions among which to choose". ${ }^{2}$

According to the European Commission impact assessment on the IMD proposal, 'the total cross-border life insurance business was roughly 5\% in 2007. In non-life segment, the cross-border business accounts for 8\% of total non-life business "63 Cross-border activities of insurance intermediaries could at that time considered a nearly inexistent.

Most of the EU Member States implemented the IDD only at the end of 2018: it is therefore too early to clearly assess the impact of the new provisions of the IDD Chapter III on the cross-border activities of insurance intermediaries. More time is needed to have a clear perspective of the extent to which the IDD passport will actually be used, including by new market participants such as digital intermediaries.

Some interesting and positive trends have been observed in this respect in some recent reports of the EIOPA and of the ESAs. Can it be reasonably expected that these trends will be accelerated by the IDD?

In its 2018 report on "Insurance distribution Directive: Evaluation of the structure of insurance intermediaries' markets in Europe”, EIOPA has noted an steady increase of the evolution of passport notifications for insurance intermediaries and an increase in cross-border notifications by insurance intermediaries between 2013 and 2017, both on a FOE and FOS basis, hence mainly under the IMD framework.

However, as EIOPA explained, this increase has to be interpreted carefully. First there is a lack of useful data available and secondly, notifying an intention to provide services under FOS or FOE does not mean actually providing services in a host Member State. As mentioned before, intermediaries did not have the obligation to report their actual business under the IMD, i.e. the volume and products/lines of business they really mediate across borders. And this situation has not changed with the IDD. After the implementation of the IMD, thousands of Czech intermediaries, for example, had notified their intention to do business in most of the EU Member States. As it turned out, they never actually carried out any cross-border business

\footnotetext{
${ }^{62}$ ESAs report on cross-border supervision of retail financial services, 9 July 2019, JC/2019-22.

${ }^{63}$ Commission staff working document, Impact assessment, accompanying the document Proposal for a Directive of the European Parliament and of the Council on Insurance Mediation, Strasbourg, 3.7.2012, SWD (2012) 191 final.
} 
except in Slovakia. As explained in the ORIAS ${ }^{64}$ annual reports, the body that registers French intermediaries in France, since 2011 "the notifications of some 2000 Czech intermediaries operating in France must be analysed with care. In fact, the body holding the Register of Intermediaries in the Czech Republic sent a notification of operation in France for all its registered intermediaries".

It is also interesting to note that, according to the 2018 EIOPA report, a significant portion of intermediaries' notifications mainly relate to "neighbouring" Member States. For example, in France, it is predominantly insurance intermediaries from the UK, Spain, Italy, Luxembourg, and Belgium who have notified their intention to operate under FOS in France. French intermediaries, meanwhile, have similarly notified their intention to operate in these countries under FOS. This situation has been in a slow and constant evolution since 2008 .

\subsection{IDD Passport, Digitalisation and Consumers}

The 2019 ESAs report on cross-border supervisions confirms this evolution. They explained that "in monitoring consumer protection developments and financial innovations, the ESAs have noted the continued increase in the cross-border provision of financial services to consumers across of the EU. This increase is both the development of the single market in financial services and the digitalisation of financial services across the banking, insurance and securities sectors, which further enables financial institutions to provide their services across borders".

The IDD is an activity-based text: it applies to every person who is undertaking the activity of insurance distribution, whether via traditional or digital means. An increasing number of insurance intermediation business models are today partially or entirely digitised ${ }^{65}$ providing services to customers established in other Member States. It is very likely that these intermediaries operating through digital means will make increased use of the IDD passport, making its supervision even more challenging for national and EU supervisors if key issues are not solved rapidly, such as the lack of clear criteria for determining the location where services are provided.

Because the digitalisation of financial services is seen by EU regulators as a means to further integrate the single market, they are encouraging its development via regulatory 'sandboxes'. ${ }^{66}$

\footnotetext{
${ }^{64}$ Registre unique des intermédiaires en assurance, banque et finance - https://www.orias.fr/ welcome.

${ }^{65}$ On legal and regulatory issues arising from these models, see Marano (2019), pp. 294-315.

${ }^{66}$ The ESAs define in their joint report on regulatory sandboxes and innovation hubs as "scheme set up by a competent authority that provides regulated and unregulated entities with the opportunity to test, pursuant to a testing plan agreed and monitored by a dedicated function of the relevant authority, innovative products or services, business models, or delivery mechanisms, related to the carrying out of financial services".
} 
Competent authorities are however concerned about the impact on the level playing field if material divergences were to emerge between the approaches of the national competent authorities to the design and operation of such 'sandboxes', such as regulatory arbitrage. It is therefore interesting to note the ESAs believe that "regulatory sandboxes may not be used as a mechanism to dispense with requirements under EU law, such as the requirement to obtain a licence before carrying out certain financial services, such as payments services, insurance services etc. Levers for proportionality embedded into law, for instance with regard to systems and controls requirements, may be applied in the context of firms participating in a regulatory sandbox in the same way as to firms outside the sandbox". This is a key principle to ensure that sandboxes remain 'channels of distribution'-neutral.

Are clients and consumers ready to benefit from these products offered by intermediaries not established in their countries?

It is a common practice for commercial clients to employ the services of intermediaries established in other EU Member States-a diverse range of European companies rely for example on insurance coverage provided by the specialised intermediaries of the London insurance market. It is interesting to note that according to the Commission Special Eurobarometer 446 on financial products and services ${ }^{67}$ the attitude of private customers towards purchasing financial products or services on a cross-border basis is also changing, albeit very slowly. More and more are eager to buy financial products or services from a provider in another EU Member State, the proportion increasing from 5\% in 2011 to 7\% in 2016. However, there are some large differences between countries, consumers for example in Romania, Luxembourg, Cyprus and Ireland being more likely to have purchased at least one financial product or service in another EU country. However, some consumers believe that there are fewer consumer protection rules in other EU member State or simply do not know their rights if there are problems. These are clear barriers to cross-border purchases of financial products and services.

And there are other barriers that, despite the simplification of the IDD notification rules and despite the fact that insurance contracts are legal and intangible products which make them particularly suitable for cross-border sale, may make the IDD single passport still difficult to use. At a consumer level, language and cultural differences, consumer preferences and national consumer protection rules, often still act as entry barriers. At the intermediary level, the need for local risk knowledge, business and distribution characteristics as well as the occasionally abusive use of general good provisions by the host Member State as mentioned earlier, can make cross-border selling difficult. It will be interesting to study whether the need to identify a target market under POG rules as introduced by the IDD will help cross borders activities of intermediaries or, on the contrary, will create another obstacle to them.

Finally, it seems worth dedicating a final paragraph to the impact of Brexit on cross-border activities of insurance intermediaries.

\footnotetext{
${ }^{67}$ Special Eurobarometer446, Report, financial products and services, July 2016.
} 


\subsection{The Impact of Brexit on Cross-Border Activities of Insurance Intermediaries}

On 23 June 2016, the UK voted to leave the European Union. The UK had been due to leave the EU on 29 March 2019, but the departure date was revised and the UK in fact left the EU on 31 January 2020 with a Withdrawal Agreement. The UK has entered a transitional period, which is due to operate until 31 December 2020. During the transition period, EU law continues to apply in the UK.

Once the UK becomes a "third country" under EU legislation, the IDD will no longer apply to UK intermediaries (only the UK requirements will continue to apply) and UK intermediaries will be no longer treated as EU intermediaries. UK intermediaries will lose the IDD passporting rights they currently enjoy and similarly, EU intermediaries will lose the IDD passporting rights in relation to the UK.

In most EU Member States, governments have adopted legislative acts on the UK's withdrawal from the EU providing for contingency measures should there be a 'hard Brexit' (i.e., UK withdrawal with limited alignment). This will ensure that policyholders with existing life and non-life insurance policies with UK insurers undertakings, operating in their respective countries in FOE or FOS under the Solvency II single licence, will not be affected by these insurers losing their passport rights. Most of these national acts of the EU Member States provide for a temporary run-off regime which, subject to a number of conditions, will enable UK insurers to continue to fulfil their obligations, contracted to their EU customers prior to Brexit, for a transitional period after the date of the UK's withdrawal from the EU. However, it is unfortunate that in many countries, UK insurance intermediaries are not included in the relevant local legislations, as during this transitional period they could help their EU 27 clients, for example to resolve claims problems on multiple insurers' London policies.

In the UK, European insurance intermediaries currently operating in the UK can continue to carry out insurance business, including writing new contracts as well as servicing existing contracts, for a temporary period after even a 'no-deal' Brexit (i.e., UK withdrawal without agreement). In order to do so, they must submit applications for UK authorisation and complete any necessary restructuring.

The interpretation of Articles 1 and 16 of the IDD in a Brexit context is a complex issue. According to Article 16 of the IDD on the restriction on use of intermediaries, ${ }^{68} \mathrm{EU}$ intermediaries are permitted to use only the insurance distribution services of other EU registered intermediaries.

When reading Article 1 on the scope of the IDD in parallel with Article 16, one can wonder about the possible unintended consequences of Article 16 in a Brexit context. The IDD does not apply to insurance distribution activities in relation to

\footnotetext{
68“Member States shall ensure that, when using the services of the insurance, reinsurance or ancillary insurance intermediaries, insurance or reinsurance undertakings and intermediaries use the insurance and reinsurance distribution services only of registered insurance and reinsurance intermediaries or ancillary insurance intermediaries including those referred to in Article 1(3)."
} 
risks and commitments located outside the Union ${ }^{69}$ or insurance distribution activities carried out in third countries. ${ }^{70}$ Further, the IDD does not affect a Member State's law in respect of insurance or reinsurance distribution activities pursued by intermediaries established in a third country and operating on its territory under FOS. $^{71}$

It is however not clear which activities are exactly covered by Article 1, as no definition is given in the IDD of the EU Member States in which the risk or the commitment are situated (unlike the Solvency II Directive). Therefore, Member States have differing interpretation of where activities of intermediaries take place.

Although it is known that it was not the intention of the IDD, Article 16 could mean that EU intermediaries are not permitted, even if their national law so provides, to accept/place risks located in the EU, with third country intermediaries, i.e. who are not registered in the EU, such as UK intermediaries post-Brexit.

This of course would significantly restrict choice and competition for insurance products to the detriment of EU clients. Insurance intermediaries very often work in collaboration with colleagues in other non-EU markets. This ensures that the client, via the intermediaries' cooperation, has access to local expertise in the respective markets which are part of the insurance contract or related risk services. The ability to access third countries' capacity also widens the pool of available products for their EU consumers and can allow them to obtain vital coverage that might not be available in EU.

Effectively shutting the EU off from global markets was clearly not the intention of the EU regulators. During the adoption process of the IDD, the EU co-legislators had agreed that clarity was needed to ensure that intermediaries registered within the EU could still work with those outside of the EU, that the IDD did not aim to exclude international activities of the European intermediaries. ${ }^{72}$ Article 16 was even deleted for a while. ${ }^{73}$ However, no such clarity was introduced in the final version of Article 16 and it is unfortunate that it leaves the door open to possible restrictive interpretations.

\footnotetext{
${ }^{69}$ Insurance Distribution Directive, Article 1(6) subparagraph 1.

${ }^{70}$ Insurance Distribution Directive, Article 1(6) subparagraph 3.

${ }^{71}$ Insurance Distribution Directive, Article 1(6) subparagraph 2.

${ }^{72} \mathrm{~A}$ draft Article $16 \mathrm{read}$ as follows: "Member States shall ensure that, when using the services of the insurance or reinsurance intermediaries established in the EU, insurance and reinsurance undertakings and intermediaries use the insurance and reinsurance mediation services only of registered insurance and reinsurance intermediaries or of the persons referred to in Article 1(2) or of the persons who have fulfilled the declaration procedure referred to in Article 4."

${ }^{73}$ The Council, until the very last trilogue meetings, had deleted Article 16 as "it was considered superfluous. The scope of the Directive is already laid down in Article 1". Then it seems that in the end Article 16 was reintroduced because of Article 33.1 b) on Sanctions. However, it is clear that Article $33.1 \mathrm{~b}$ ) refers to intermediaries or insurers using the insurance or reinsurance distribution services of persons referred to in Article 3 that covers intermediaries registered with the competent authority in an EU Member State.
} 
In its February 2019 Recommendations ${ }^{74}$ for the insurance sector, in light of the UK withdrawing from the EU without a withdrawal agreement, and in particular in its Recommendation 9 on insurance distribution, EIOPA confirms that the IDD applies only to distribution activities to EU27 policyholders and for EU27 risks:

Competent authorities should ensure that UK intermediaries and entities which intend to continue or commence distribution activities to EU27 policyholders and for EU27 risks after the UK's withdrawal are established and registered in the EU27 in line with the relevant provisions of the IDD. (...). When assessing whether a specific UK intermediary or entity is providing distribution activities in the EU, competent authorities should take into account that only the consistent and uniform application of the IDD can guarantee the same level of protection for consumers and ensure a level playing field in the Union. Competent authorities should ensure that all intermediaries carrying out distribution activities which target EU27 policyholders and EU27 risks fall under the scope of the IDD. For this purpose, competent authorities should assess any distribution model against the definition of distribution activity as provided for in the IDD.

The activities outlined above will be subject to local Member State regulations or supervisory requirements and therefore there is potential for divergent approaches and practices in each of the EU Member States. UK and European intermediaries will need to consider carefully whether their arrangements leave them exposed to potential legal and regulatory risk through acting without regulatory permission.

\section{Final Remarks}

The IDD's main objective to further facilitate the cross-border activities of insurance intermediaries, thus promoting the emergence of a genuine internal market in insurance services, was bold and audacious.

But an EU legislative text is always the product of compromises. Despite the improvements introduced by the IDD such as a real simplification and clarification of the FOS and FOE notification procedures or more transparency on general good rules, the opportunity was missed to clarify the badly-needed criteria for determining when an intermediary is deemed to be transacting business on a FOS basis in a host Member State, thus having to comply with the general good rules of that State. This clarity was also key for national supervisors given the increasing powers given by the IDD to competent authorities of host Member States.

Even if businesses can currently rely on EIOPA common understanding of FOS, it does not originate from EU secondary legislation and has its potential limitations.

\footnotetext{
${ }^{74}$ The Recommendations provide guidance on the treatment of UK insurance undertakings and distributors with regard to cross-border services in the EU after the withdrawal of the UK from the EU without a withdrawal agreement. EIOPA explains that the objective of its Recommendations is to minimise the detriment to policyholders with cross-border insurance contracts. The Recommendations addressed to National Competent Authorities are to foster supervisory convergence and to ensure consistent supervisory practices.
} 
Time will soon tell whether the new exceptional powers given to host Member States over intermediaries operating in their territories, combined with an excessive use of general good rules - in particular in areas of the home Member State competence such as registration requirements-will emerge as being serious obstacles in practice to the IDD single licence. This could well happen, in particular given the current context where recent failures of insurers operating in some Member States under FOS or FOE have led Member States to start revising the access to their respective markets.

The current review by the European Commission of the Solvency II Framework will need to bring solutions to this serious issue.

Finally, the IDD single licence is not used in isolation. There remain important obstacles to the cross-border activities of insurance intermediaries: they relate for example to areas like taxation or labour law, languages and culture, including expectations of the local policyholder. And these obstacles will never be addressed by the IDD.

Acknowledgements The author would like to thank Rebekka de Nie, EU Policy Manager at BIPAR, and Stella Mitta, legal assistant at BIPAR, for their generous assistance.

\section{References}

BIPAR/Steptoe: The insurance Distribution Directive: A handbook on cross-border insurance distribution by insurance intermediaries - January 2019

Debuisson B. La distribution transfrontalière des produits d'assurance. Plongée en eaux troubles, Université Catholique de Louvain, 1996 - Doc 96/26

Marano P (2019) Navigating Insurtech: the digital intermediaries of insurance products and customer protection in the EU. Maastricht J Eur Comp Law pp 294-315

\section{Legislation}

Commission Recommendation 92/48/EEC of 18 December 1991 on insurance intermediaries EIOPA Decision of the Board of Supervisors on the cooperation of the competent authorities of the Member States of the European Economic Area with regard to Directive (EU) 2016/97 of the European Parliament and of the Council of 20 January 2016 on insurance distribution - EIOPABoS/18-340

EIOPA: Insurance Distribution Directive - Report analysing national general good rules - 22/07/ 2019

EIOPA - Country-by-country analysis of national general good rules - Annex III to the Insurance Distribution Directive: Report analysing national general good rules, - Romania, page 82

ESAs report on cross-border supervision of retail financial services, 9 July 2019, JC/2019-22

OJ of the EC, C43/5 - 16-2 -2000 - Commission interpretative communication on the freedom to provide services and the general good in the insurance sector 


\section{Documents}

Document de position: Renforcer le marché intérieur en luttant contre les défaillances d'entreprises d'assurance qui opèrent par voie de LPS. https://www.ffa-assurance.fr/

Registre unique des intermédiaires en assurance, banque et finance - https://www.orias.fr/welcome Special Eurobarometer 446, Report, financial products and services, July 2016

Open Access This chapter is licensed under the terms of the Creative Commons Attribution 4.0 International License (http://creativecommons.org/licenses/by/4.0/), which permits use, sharing, adaptation, distribution and reproduction in any medium or format, as long as you give appropriate credit to the original author(s) and the source, provide a link to the Creative Commons licence and indicate if changes were made.

The images or other third party material in this chapter are included in the chapter's Creative Commons licence, unless indicated otherwise in a credit line to the material. If material is not included in the chapter's Creative Commons licence and your intended use is not permitted by statutory regulation or exceeds the permitted use, you will need to obtain permission directly from the copyright holder.

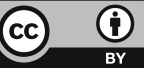

